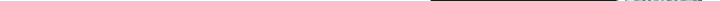





\section{MEMORIAL sobre as terras do córrego "Burity", formado do Cachoeirão, affluente do Rio Aquidauana*}

Fernando Augusto Azambuja de Almeida**

A conseqüência da guerra do Brasil contra o Paraguai foi desastrosa, causando a dispersão das aldeias Terena por uma vasta região. Este fato poderia ter sido um evento passageiro, mas, ao contrário, abalou, irreversivelmente, a estrutura social Terena, com a perda das suas terras tradicionais. Findo o conflito, quando começaram a retornar aos seus territórios tradicionais, estes já haviam sido tomados, em grande parte, por terceiros. A partir daí, começa uma nova etapa na vida dos Terena, que passam de grandes guerreiros na luta da conquista do território brasileiro à fornecedores forçados de mão-de-obra semi-escravizada nas fazendas implantadas em seus territórios tradicionais.

O Memorial redigido pelo o delegado de inspeção de índio Nicolau Bueno Horta Barbosa, datada em 13 de dezembro de 1927. mostra a realidade dos Terena da Invernada Burity naquele período, onde os índios eram explorados como mão-de-obra dos fazendeiros e que sentiam falta da vida livre nas matas da Inverna Buriti onde viveram por muitos anos. Muitas vezes os Terena se refugiavam nas matas se salvando dos busos dos fazendeiros nos trabalhos,

No primeiro momento com a demarcação da fazenda das Correntes, o alto Buriti ficou fora da demarcação, ficando para os Terena que ali habitavam, porém com a descoberta das sobras de terras da dita fazenda, outros requerentes começaram a chegar e ocuparem área ocupadas pelos índios que há muito tempo estavam ali.

\footnotetext{
* Este documento foi digitado, pois não tinha condições de ser copiado por estar ilegível. O mesmo se encontra no rolo de microfilme n. 224 no Museu do Índio - RJ e pertence à Coleção Comissão Rondon.
}

** Graduado em História, coordenador técnico do Centro de Documentação Teko Arandu/NEPPI/UCDB e do Laboratório de História LABHIS/UCDB/Campo Grande-MS azambujahist@yahoo.com.br 
Os Terena com suas aldeias pomares e roças foram sendo empurrados para as sobras das demarcações feitas pelos fazendeiros requerentes das terras da Invernada Burity, abaixo de ameaças e retaliações como: soltavam os animais nas roças dos Terena para serem destruídas. Eram acusados de crimes, divulgando um descrédito sobre os indígenas daquele local, assim impedindo qualquer tentativa de reclamação sobre a terra.

O Cel. Nicolau Bueno Horta Barbosa diz ainda no texto que os fazendeiros lançaram várias difamações contra os Terena, ele indignado lembra que foi os indígenas da Inverna Buriti que fundou as fazendas na região, que construiu as sedes, os engenhos, trabalhou no feitio da farinha, da rapadura e nos carros de boi e foi eles abriram a primeira estrada apara automóveis na região.

O inspetor ainda escreve que a especulação de terras era grande em toda a região, onde em nenhum momento foi pensado ou foi respeitado o direito dos Terena que estavam com suas roças e benfeitorias na Invernada Buriti. Além disso o autor do Memorial tinha a esperança que O Governo do então Mato Grosso fosse reservar 2.600 hectares para a mesma.

Este Memorial nos mostra que o governo do estado "confundiu", a legislação e considerou as terras da Invernada Burity como devolutas passando a disputar sua regularização com as posses comuns sujeitas à legitimação. E que o Serviço de Proteção ao Índio, SPI, não tinha força política e nem conhecimento sobre o conceito de ocupação indígena, pois nada foi feito para que a Invernada Buriti, ou Colônia dos Índios ficasse preservada das demarcações terras requeridas pelos fazendeiros.

\section{MEMORIAL sobre as terras do córrego "Burity", formado do Cachoeirão, affluente do Rio Aquidauana}

A “Colônia ou aldeamento tereno. Sua origem. Repetidas solicitações dos índios para que lhes sejam resevadas as terras que ocupam. As invasões e estado actual da questão.

Entre os latifúndios de que muitos fazendeiros se apossaram antes de qualquer cultivo systematico, ou mesmo antes de qualquer conhecimento alem das conjecturas, ou simplesmente baseado nas viagens a cavalo - figurava a fasenda das Correntes, hoje repartida entre muitíssimo condôminos.

Encostada ao S.E. nas quebradas da serra de Maracaju, era natural que seu proprietário conhecesse pessoalmente e não a cultivasse nos recantos ermos das furnas, sombreados de mattas grossas, por onde correm a principio os córregos que se despenham serra-abaixo, para depois irrom- 
perem nos campos de cerradão; onde de longe são reconhecíveis os seus valles profundos pela cor verde escura das densas mattas de taquarussu.

Em um desses lugares ermos, defendidos pela agreste das visitas incomodas dos civilizados ocultou-se por muito tempo um grupo de índios guaranys, que as vezes erão conhecidos por chavantes, outras vezes por uaxirys.

Acostada ao Aquidauana, a sede da fasenda das Correntes desta mais ou menos $60 \mathrm{~km}$ em linha recta de local tão ermo, distancia esta que valia muitíssimo mais pelos cerradões que a enchem.

Vaqueiros e roceiros de todas as fasendas do sul do Estado, não tardou que os índios terenos viessem em varias turmas servir ao fasendeiros das Correntes; e, internado-se pouco a pouco pelo seu natural pendor de procurar a tranqüilidade nas mattas, chegavam até onde os aldeavam os seus irmãos uaxirys, a que se foram juntando em mutuo apoio. Assim, em desejando salários, serviam ao seu patrão fazendeiro: mas, tangidos pela nostalgia da vida livre selvatica, buscavam os ermos do Burity, e muitos annos passaram assim.

Sobrevindo as lutas civis, o fasendeiro entregava suas tropas e rebanhos a vizinhos à fidelidade dos índios terenos, que o levavão ao ermo do Burity onde facilmente de salvavão dos abusos dos próprios a taes epochas. Dahi a denominação de invernada para o local, como a de Colônia em referência aos índios. Esses factos vem abonar a conducta desses terenos, muito em desaccordo com a mais recente campanha de descrédito, que tão injustamente lhes tem movido os actuaes interessados nas terras que elles occupam.

Fosse movido por um natural escrúpulo de consciência, fosse porque em verdade reconhecesse que o alto Burity, onde se alojavam os índios, não fazia parte da Posse registrada, o certo foi que, por occasião da demarcação das Correntes, o proprietário concordou em que aquellas terras ficassem fora do seu perímetro.

A planta levantada por occasião da revisão e divisão judiciária das Correntes - repitiu a exclusão, em obidiencia aos documentos legaes. E desse modo que, sem mais nenhuma contestação, sobraram as terras onde os terenos habitavão, habitam, em ambas as margens do Burity, ora sob a demarcação de "Invernada", ora e mais geralmente, sob o de "Colônia".

Por esse tempo, porem, já os cubiçosos haviam apparecido; e tanto que, servindo-se da opportunidade em que se confirmaram as sobras da fasenda das Correntes, apressarem-se o requerer as terras occupadas e lavradas pelos índios, sem que os indefesos por natural ignorância e afas- 
tamento, pudessem reclamar immediatamente em fórma legal a bem de seus direitos.

Despertaram elles, porem, quandos os intrusos providenciaram sobre as demarcações, precedidas alias de um período em que os índios foram perseguidos em suas roças, onde soltavão aquelles as suas criações; ameaçados em suas vidas, accusados de vícios e crimes que nunca haviam commetido, etc.; tudo como preparativo da espoliação prestes a effetivar-se.

De um lado o Sr. Agostinho Rondon ou seu preposto; de outro o Sr. Cel. Porfhirio De Britto ou seu preposto Rabello, de outro ainda o Sr. José de Souza, etc.; porfiavam em amedrontar e prejudicar aos terenos por todas as formas, até que enfim se animar a chegar com o demarcador, que afincou os marcos dentro mesmos das Aldeias, por entre os ranchos e roçados, em nome do irrisório d i r e i t o conferido por um título provisório dolosamente obtido pelo Governo, pois que systematicamente allegaram em seus requerimentos uma cultura que não tinham, occupação que não faziam sinao por esbulho; ao mesmo tempo que occultavam a circunstancia de exisitiram nas terras requeridas as aldeias indígenas com suas roças e mais trabalhos!

Antepostos os primeiros obstáculos a tanta extorção, não tardou aos interessados abrissem a campanha de diffamação contra os humildes terenos, passaram a ser accusados de vadios, ladrões,....;elles que foram os braços para a fundação e cultura das fasendas: elles que abriam os carros de boi e carrearão para seus accusadores; elles, que trabalham na farinha, no assucar,na rapadura e no alambique dos detractores; elles que lavraram e cortaram as madeiras para as casas destes; finalmente, elles, que foram - sózinhos - os constructores da única estrada de autos da região!

Actualmente, pois, que perdura a injustiça contra os terenos do Burity, covem dizer que o Sr. Agostinho Rondon, requerente que levou sua ambição ao ponte de fazer demarcar para si toda uma aldeia principal, com suas roças, casas e pomares situada no pontal do Burity com o Cortado;Agostinho Rondon há muitos annos que não mora por lá, si é que já teve morada naquellas terras. Abandonado de seu preposto, que se mudou para as cercanias de Nioac, não tendo ainda conseguido vender as terras que pretende extorquir, nada cultiva no Burity.

O Sr. Porfhirio de Britto, não havendo também conseguido especular com as terras que fez demarcar dolosamente, por haver pedido um preço duplo que combinara - perdeu também o seu preposto Rabello, o rancoroso ameaçador dos índios. 
Outros ao norte, mais felizes, já especularam passando a outras mãos a terra que deviam estar com os terenos.

Por toda a parte, pois, uma especulação adiada ou perdida; ou uma especulação realizada. Ahi se denota o móvel de tanta ambição de terras!

Melhor fora que as deixassem nas mãos calózas dos índios terenos.

AREA - Considerando, não a área effetivamente occupada pelos índios, mas sim apenas o restante após as compras feita ao Estado por particulares e definimos limitando

1 - ao norte com as terras do Varjão, já demarcada e pertencente a

Reginaldo Lemos da Silva

2 - ao poente com as terras demarcadas da fazenda das Correntes

3 - ao nascente com as terras demarcadas do Alegre de José Diogo de

Souza, as de Adelino de Souza, S. Bento de Porphirio de Britto

4 - ao sul com as mesmas terras demarcadas de Porphirio de Britto, e as

pretendidas por Agostinho Rondon

Sendo irremediável a situação creada pelas compras de terras feita ao Estado por José Diogo de Souza, Adelino de Souza, Reginaldo Lemos da Silva e Porphirio de Britto, cujas demarcações foram approvadas; se fica em discussão e limites das pretendidas por Agostinho Rondon, que ainda não effetivou a compra, não tendo portanto o título definitivo e parecendo mesmo que a sua pretensão cahiu em comisso.

Si prevalecessem os desejos desse candidato, lhe caberia uma aldeia inteira do Burity, a sede justamente da Colônia, com todas as suas benfeitorias e área restante, apertada entre o córrego Barreirinho ao norte e o Cortado ao sul não terá mais do que 2.200 hectares.

Mas é de interíssima justiça e equidade que Agostinho Rondon não leve suas ambições além das roças e benfeitorias que seu preposto realisou há tempos, alias com o braço indígena; ficando por outro lado os índios com a delles, de modo que o limite a traçar-se corra de permeio, a umas e outras, caso em que a área a ser concedida pelo Governo attingirá a 2.600 hectares.

Campo Grande 23 de dezembro de 1927

Nicolau Buenos Horta Barbosa

Delegado da Inspetoria de Índios

Recebido em 18 de julho de 2008.

Aprovado para publicação em 28 de julho de 2008. 
